\title{
The coming-of-age of tourism: embracing new economic models
}

\author{
Pauline J. Sheldon
}

Pauline J. Sheldon is based at TIM School, University of Hawai'i at Manoa, Honolulu, Hawaii, USA.
Received 2 March 2021

Revised 6 May 2021

Accepted 6 May 2021

(C) Pauline J. Sheldon.

Published in Journal of Tourism Futures. Published by Emerald Publishing Limited. This article is published under the Creative Commons Attribution (CC BY 4.0) licence. Anyone may reproduce, distribute, translate and create derivative works of this article (for both commercial and non-commercial purposes), subject to full attribution to the original publication and authors. The full terms of this licence may be seen at http://creativecommons. org/licences/by/4.0/legalcode

\begin{abstract}
Purpose - The purpose of this paper is to re-examine the economic models and assumptions that have given rise to current day tourism. It suggests alternate models based on new values to help tourism emerge from the current COVID crisis and "come-of-age."

Design/methodology/approach - The paper delineates the assumptions of neoliberal economics upon which much of tourism has been based. It then summarizes the work of progressive economists in developing new models that value capital other than financial. Six of these models are briefly described and applied to tourism.

Findings - Some assumptions underlying the neoliberal economic model that need re-examining are the ideas that: self-interest drives ideal economic behavior; success comes from competition, not cooperation; encouraging consumption for its own sake; giving owners priority over other stakeholders; and more income translates into more happiness. Redesign of economic systems requires consideration of social capital, natural capital, intellectual capital, compassion capital, trust capital and spiritual capital to name a few. Examples of alternate systems using these capitals are the collaborative economy, the circular economy, the creative economy, the gift economy, the sacred economy and the regenerative economy.

Originality/value - The paper's approach is to interlace modern economic thought with the future maturation of tourism and to suggest that tourism policymakers and leaders learn from these thinkers to create a new model for the future of tourism.
\end{abstract}

Keywords Values, Circular economy, Tourism futures, Collaborative economy, Economic models, Regenerative tourism

Paper type Viewpoint

\section{Introduction}

Civilization is being threatened in ways it never has before, presenting new realities, new norms and new shocks. Tourism is intimately connected to these startling changes: pandemics, climate change, political instability, human rights, immigration and border issues, to name a few. As a result, New Zealand and many other destinations are reeling from an abrupt lack of revenue, in contrast to the past decade, when tourism grew to unsustainable volumes in many locations. This rampant growth has created a hugely consumptive industry, generating large amounts of pollution and waste, destroying ecosystems, increasing social inequities and growing beyond sustainable levels. Calls for a critical reconsideration of this growth model are strong (Ateljevic, 2020; Benjamin et al., 2020; Goessling et al., 2021; Lew et al., 2020) and more resilient and regenerative tourism models are needed.

The current inflexion point could be likened to a "coming of age" of tourism globally. The years of tourism's exuberant "youth," often involving over-consumption and little care for consequences, are coming to an end. With adolescence comes the cessation of physical growth and the system's energy and resources develop other more refined aspects of the individual (Eisenstein, 2011, p. 109). Similarly, as tourism's physical growth stops, other 
considerations such as quality, caring and community well-being must now be given priority. The individual coming-of-age process is also often due to a shock which creates a moment of epiphany. The COVID pandemic has created that shock for tourism. Maturation to "adulthood," for both the individual and tourism, requires learning, inner reflection, taking responsibility for consequences of choices made and a commitment to wiser choices.

This inner reflection includes questioning tourism's future role in society. Questions such as: How can tourism be re-designed to be a force for the greater good? How can tourism be relevant to the whole of society and contribute to solving its systemic crises? How can tourism address the greed (corporate and personal), massive income inequities and excessive "me-ness" that has driven much tourism behavior in the past? How can values from the world's philosophical and spiritual traditions such as the inter-connectedness and interdependence of all life and systems-thinking be integrated into tourism design? Careful reflection of these and similar questions could lead to wiser, long-term choices and a more resilient future for tourism. New Zealand is already taking steps to answer these questions, yet there is more work to do.

This paper suggests further that the economic system upon which most of tourism has been built is substantially responsible for the "adolescent" behavior of tourism to date. It proposes alternate economic frameworks based on different value systems to design a more mature, responsible tourism future for New Zealand. However, this first requires letting go of old patterns of behavior.

\section{Letting go of the old}

"Historically, pandemics have forced humans to break with the past and imagine their world anew. This one is no different. It is a portal between one world and the next. We can [...] walk through it, dragging the carcasses of our [...] avarice, our data banks and dead ideas, our dead rivers and smoky skies behind us. Or we can walk through lightly, with little luggage, ready to imagine another world." (Roy, 2020, p. 1)

The quote above suggests that old "luggage" in the form of beliefs, assumptions and frameworks, must be relinquished to imagine a new world. Visionary economists agree that a sustainable future requires that individuals, firms and governments re-assess their value systems, behavior patterns and lifestyles to come into balance with each other and with nature. Otto Sharmer, even prior to the pandemic said "We live in an age of profound disruption; suffering from 'maximum me,' 'bigger is better,' and special interest group decision-making which has led to 'organized irresponsibility' and has collectively created results that no-one wants" (Sharmer and Kaufer, 2013, p. 190). This call to shift from egoeconomics to eco-economics speaks to the transformation of thinking required in tourism away from self to other. The problems of the economic growth model are also expressed by Charles Eisenstein "[...] the money system has contributed to alienation, competition, and scarcity, destroyed community and necessitated endless growth" (Eisenstein, 2011, p. 10). And Naomi Klein adds her criticism of the old economic value system: "Drop the addiction to pure free-market ideologies, put an end to greed and corporate power and restructure local economies and strengthen democracies" (Klein, 2014, p. 17).

These are a few of many voices calling for change, yet tourism seems to be outside of this progressive socio-economic debate. The current crisis demands that tourism "grow up" and align with the broader endeavor by other economic sectors to create a more sustainable and regenerative world. Effectively, the pandemic has "sent tourism to its room" to think about its behavior, and to realize that capitalism and the neo-liberal economic system upon which it has based its past success are crumbling.

Examining the assumptions of these economic systems is the first step to re-imagining New Zealand tourism anew. In brief, some of the assumptions underlying these economic models that have determined tourism's development are as follows: 
self-interest drives ideal human behavior;

- only competition can lead to economic progress;

- more income equals more happiness;

- markets are fair and prices tell the truth;

- encouragement of consumption for its own sake;

- focus on the short-term;

- overvaluing owners versus other stakeholders;

- considering gross domestic product (GDP) growth as the most important measure; and

- ignoring human values (perhaps the most limiting of all).

Questioning these assumptions can create an opening for new economic paradigms to guide tourism forward based on different and more mature value systems. The next section will explain how mainstream economists are embracing new value systems and how New Zealand tourism can learn from them.

\section{Embracing new value systems}

For decades economists have been chipping away at the need for new economic systems based on different assumptions and values. In 1973, Schumacher injected spiritual questions into economic ones, thereby broadening the field of economic decision-making and behavior with his book "Small is Beautiful: Economics as if People Mattered" (Schumacher, 1973). In 1985, The New Economics Foundation was created by economists seeking to create a purposeful economy, a decent quality of life, more worker power, homes for all and a transition to a green economy. Other economic initiatives working to foster similar value shifts include: the WellBeing Economy Alliance; the WE7 Group of Wellbeing Economies (in contrast to G7); the Centre for Understanding Sustainable Prosperity; and the Green Economy Coalition. As recently as 2019, a group of mainstream economists led by Nobel Laureate Joseph Stiglitz progressed this work to redefine societal well-being. They challenged important concepts in economies, including GDP as a measure of progress and suggested a "dashboard" of quality-of-life indicators such as equality, physical and mental health, education, happiness, innovation and restoration of damaged eco-systems (Stiglitz et al., 2019). Kate Raworth, an economist at Oxford University also critiques the economic growth model and suggests that pursuing profit is worthless if it is at the cost of humanity (Raworth, 2017). She suggests a different economic model, called doughnut economics, which balances social equity and progress within the environmental constraints of growth, requiring new values, new priorities and new metrics.

The common thread linking these economists' contributions is the need for economic activity to focus on the greater good. The greater good embraces the idea that all creatures have a shared destiny, a collective purpose and a common future and decisions made with that in mind are needed now. This is not a new idea: Aristotle, Thomas Aquinas and others throughout history have espoused it. It requires shifting from "what about me, my pleasure, my wealth?" to "what can I do to contribute to others and the world?" To support this shift, alternate metrics and indices have been designed such as The Happy Planet Index; the Genuine Progress Indicator; and Gross National Happiness and UN Sustainable Development Goals. The next section examines six new economic frameworks to help bring about the greater good. 


\section{Exploring new economic structures for tourism}

New economic models must conceptualize transactions differently by re-defining the resources or the forms of capital that are exchanged. To stimulate the greater good rather than selfish ends, value must be given to other forms of capital besides financial capital. Identifying and valuing alternate capitals such as social capital, natural capital, trust capital, compassion capital, innovation capital, cultural capital, experiential capital and intellectual capital are the basis of re-defining a new economic scaffolding for society and for tourism. As these are given value (as in many indigenous cultures) the nature of tourism shifts away from only transactional, financial activities to include ones based on relationships, creativity and other human values such as compassion, trust, generosity, integrity, honesty and courage. These alternate capitals, even though hard to measure, are not scarce or easily depleted when used, as is financial capital. Human beings have an ever-replenishing supply of many of these capitals. Six of the new economic structures valuing these alternate capitals are mentioned below and the relevance of each to more mature tourism is discussed.

\subsection{The collaborative or sharing economy}

The sharing or collaborative economy, perhaps the most common alternate economic model, challenges economic ownership and proposes a system in which assets or services are shared, either freely or for a fee. The collaborative economy creates new marketplaces and is "shaking the very bedrock of an industrial system sustained on commercial value chains" (Dredge and Gylmothy, 2017, p. 1). The neoliberal assumptions of "overvaluing ownership" and "only competition can lead to growth" are brought into question in this economic framework. The collaborative economy has its roots in the non-monetized sharing and gift economies. Tourism offers many innovative options for agents to share resources, such as vehicle sharing (bicycles, cars), accommodation sharing or exchanges, couchsurfing and home hosting of dinners and other events. Even though Airbnb and Uber with their digitally-mediated, monetized transactions have experienced success, they have somewhat distorted the ideal of the model. A truer example of the sharing economy is the city of Amsterdam which is Europe's first Sharing City, now followed by many others. In these cities, infrastructures are created so that residents and tourists can share or rent products and services as needed. For a successful collaborative economy, social capital is important as it creates the networks to identify shared resources. Also, trust capital is needed to enable transparent and open cooperation between agents.

\subsection{The economy of resource efficiency/circular economy}

The circular economy or the economy of resource efficiency has a mission to save resources (mostly natural resources), by using them with maximum efficiency and minimizing their wastage. It is an important part of building a mature destination economy and seeks eco-system balance and re-cycling and re-using resources. It challenges the neoliberal assumptions of "focus on the short term" and "encourage consumption for its own sake." Also by considering negative externalities, it challenges the idea that "markets are fair and prices tell the truth." Given that tourist activity has traditionally been quite wasteful (food wastage, water over-use, unused amenities in hotels, etc.) there are many opportunities to develop this type of economy. Encouraging tourism enterprises to adopt green practices such as re-cycling tourist-generated waste and using green energy and bringing awareness to tourists' sustainable choices with measures such as tourist's carbon footprint, can both help to develop a circular economy. An example of amenity recycling is Clean the World - a social enterprise partnered with large hotels to clean and recycle unused hotel soap, then sending it to countries in need. The circular economy shifts the focus from financial capital to the protection of natural capital and resources. It also uses 
intellectual capital to design creative solutions to maximize resource efficiency and minimize negative externalities from tourism.

\subsection{The creative economy}

The creative economy turns the attention from financial capital to the unleashing of human creativity, intelligence and energy. Knowledge, reasoning and creativity are needed to innovate for the immense disruptions that tourism currently faces. The measures of success for a creative economy are the amount of change, diversity, learning and adaptation that are stimulated (Howkins, 2011). Creativity is also important to include in the tourist experience and in the design of destinations (Richards, 2020). The maturation of tourism requires this learning and adaptation and improving the status, education and well-being of tourism employees is critical. Too many tourism jobs are demeaning, low paid and do not develop employees' full potential. The creation of jobs that are more meaningful and build products and services of value (beauty, clean water and air, community) will foster a more creative tourism economy. Innovative education and training programs, coupled with the private sector's commitment to invest in and enrich employees can bring about this change. The Tourism Education Futures Initiative, involving some New Zealand academics, has developed recommendations for the redesign of tourism education programs to create more capacity for meaningful careers based in values, creativity and innovation (Sheldon and Fesenmaier, 2011). Different skill sets such as mutuality, ethical awareness, stewardship, intuition, emotional intelligence and the ability to imagine and vision are needed. Social entrepreneurs and social intrapreneurs are important exemplars for this new type of tourism work. To build a creative economy for New Zealand, intellectual and knowledge capital, synergistic capital and experiential capital must be valued.

\subsection{The economy of generosity/gift economy}

A shift away from greed (corporate or personal) toward generosity is fundamental for destinations to transform and mature. Generosity as a resource is difficult to monetize but benefits the health, well-being and longevity of the giver and the receiver (Nowak, 2008; Park et al., 2017). Generosity represents a more mature behavior, whereas greed tends to typify adolescent behavior. The neo-liberal assumptions of "more income equals more happiness" and "self-interest drives ideal human behavior" are challenged in the generosity economy. Operationalizing generosity involves a change in mindset from consumption to contribution, from concern about transactions to developing trust and from isolation to community (Mehta, 2012). The circulation of generosity in a destination (by the host or the tourist) creates new networks and is foundational to a new destination economy. Research shows that increasingly tourists are altruistic and wish to contribute to the destination (Ateljevic et al., 2016), suggesting that designing experiences to foster generosity in both residents and tourists can contribute to the greater good (Sheldon, 2020). There are many around the world of examples of tourism products designed for the generosity that New Zealand may learn from. For example, Intrepid Travel, a tour operator, has designed its website so customers can, while booking their tour, gift a needy child a vacation; Karma Kitchen is an international restaurant chain which does not charge for meals, but instead invites customers to pay-it-forward for the next customer; and Amsterdam's Untourist Guide has designed experiences for tourists to help the environment such as fishing for plastic in canals. An economy of generosity for New Zealand requires the development of compassion capital, social capital, trust capital and cultural capital.

\subsection{The sacred economy}

A sacred economy reveres all people, creatures and the environment, and highlights the interconnectedness and common humanity between all. As such it is an antidote to the 
separateness and divisiveness permeating much of today's society. A sacred economy thrives on spiritual capital which is often rooted in the cultures, traditions, lifestyles and beliefs of the local and indigenous people such as the Maori in New Zealand. Such an economy respects the sacredness of place and understands the wisdom and the stories held by the culture and the land. It challenges the neoliberal assumptions of "GDP as the best measure of success" and "ignoring human values." Charles Eisenstein in his book "Sacred Economics" lays out the tenets of a sacred economy which also include de-growth, a gift culture, strengthening of local economies, equal distribution of wealth and internalization of social and environmental costs (Eisenstein, 2011). Tourism in a sacred economy places spiritual values at the center of decision-making and in the design of tourist experiences (Duda and Doburzyński, 2019). Destinations with strong spiritual traditions and beliefs can re-design more mature tourism based on these values. For example, Bhutan has based its tourism development on the spiritual values of the Buddhist tradition. While New Zealand is already embracing its own spiritual values in tourism, the continued development of spiritual capital, cultural capital and compassion capital will further nourish this kind of economy.

\subsection{The regenerative economy}

A regenerative economy is one which uses universal patterns and principles as a model for economic activity (Fullerton, 2015). It requires long-term, systemic thinking, rejects the idea that tourism is separate from the rest of the community and constantly engages the community in decision-making. It learns from patterns in nature that are constantly growing, evolving and adapting and as such is a long-term commitment to a type of tourism providing increased well-being of all living creatures (Pollock, 2019). Regenerative tourism heals damaged destination resources and contributes to thriving host communities. Each destination's regenerative path is unique and cannot easily be tracked by a standard set of indicators, as with sustainable tourism. Similar to the sacred economy, indigenous people, cultures, wisdom and values play an important role in defining a regenerative path for tourism. As an example, the Hawaiian Islands are strategizing a more mature, postpandemic tourism based on native Hawaiian values [such as malama (caring) and kuleana (responsibility)] (Hawaii Tourism Authority, 2020). Their regenerative approach also includes extensive processes to gather community input in determining the future path for tourism. Regenerative tourism, currently being developed in New Zealand, represents a comprehensive and mature approach to designing the future of tourism and incorporates many of the other five systems discussed above.

In summary, the six alternate economies discussed above all focus on building capital in addition to financial capital. They are not mutually exclusive systems but overlap in many ways. They all have in common, however, a more mature approach to tourism development for New Zealand, representing its coming-of-age.

\section{Conclusion}

The maturation of tourism beyond its adolescent stage is not an easy transition, but a necessary one given the current state of the world. It will require a fundamental change in values by all tourism stakeholders so that the greater good for all beings motivates their activities. This process is already underway in New Zealand, positioning it to be a role model for other destinations. Early adopters of this new paradigm, such as tourism social entrepreneurs, can serve as bridge-builders to the new value system and deserve encouragement and support in their endeavors (Sheldon and Daniele, 2016). Deep reflection and learning by all involved will support the transition and the thinking of progressive economists and other scholars can provide insight, inspiration and direction for tourism leaders and policymakers as they grapple with the future. For too long, tourism has been in a separate silo from other sectors, without embracing the latest thinking from allied 
fields. Transitioning New Zealand tourism to the new paradigm will be a long-term process, requiring institutional innovation founded in profound value change (Brouder, 2020). It will also require stakeholders to collaborate not compete; and tourists, residents and institutions to act with generosity, caring and creativity. When tourism "comes of age" and walks through the portal to a new era, its unique power to contribute to the well-being of all living beings in New Zealand can be realized.

\section{References}

Ateljevic, I. (2020), "Transforming the (tourism) world for good and (re)generating the potential 'new normal'”, Tourism Geographies, Vol. 22 No. 3, pp. 467-475.

Ateljevic, I., Sheldon, P. and Tomljenovic, R. (2016), Global Report on the Transformative Power of Tourism, UNWTO, Madrid.

Benjamin, S., Dillette, A. and Alderman, D. (2020), "We can't return to normal': committing to tourism equity in the post-pandemic age", Tourism Geographies, May, Vol. 22 No. 3, pp. 476-483.

Brouder, P. (2020), "Reset redux: possible evolutionary pathways towards the transformation of tourism in a COVID-19 world", Tourism Geographies, May, Vol. 22 No. 3, pp. 484-490.

Dredge, D. and S. Gylmothy, (Eds) (2017), The Collaborative Economy and Tourism, Perspectives, politics, policies and prospects, Tourism on the Verge, Springer, p. 323.

Duda, T. and Doburzyński, D. (2019), "Religious tourism vs sacred space experience: conflict or complementary interaction?", International Journal of Religious Tourism and Pilgrimage, Vol. 7 No. 5, doi: $10.21427 / 38$ th-3e38.

Eisenstein, C. (2011), Sacred Economics: Money, Gift and Society in the Age of Transition, North Atlantic Books, Berkeley, CA.

Fullerton, J. (2015), Regenerative Capitalism, The Capital Institute, available at: www.capitalinstitute.org.

Goessling, S., Scott, D. and Hall, C.M. (2021), "Pandemics, tourism and global change: a rapid assessment of COVID-19", Journal of Sustainable Tourism, Vol. 29 No. 1.

Hawaii Tourism Authority (2020), "Strategic plan”, available at: www.hawaiitourismauthority.org

Howkins, J. (2011), The Creative Economy, Penguin, London, p. 267.

Klein, N. (2014), This Changes Everything: Capitalism vs the Climate, Simon and Schuster, New York, NY, p. 576.

Lew, A., Cheer, J., Haywood, M., Brouder, P. and Salazar, N. (2020), "Visions of travel and tourism after the global COVIS-19 transformation of 2020", Tourism Geographies, Vol. 22 No. 3, pp. 455-466.

Mehta, N. (2012), "Designing for generosity”, TEDxBerkeley Talk, No. February.

Nowak, M. (2008), “Generosity: a winner's advice”, Nature, Vol. 456 No. 7222, p. 579.

Park, S., Kahnt, T. and Tobbler, P. (2017), "A neural link between generosity and happiness", Nature Communications, Vol. 8 No. 1, p. 10.

Pollock, A. (2019), "Regenerative tourism: the natural maturation of sustainability", available at: www. Medium.com

Raworth, K. (2017), Doughnut Economics: Seven Ways to Think like a 21st-Century Economist, Chelsea Green Publishing, VT, p. 320.

Richards, G. (2020), "Designing creative places: the role of creative tourism", Annals of Tourism Research, Vol. 85.

Roy, A. (2020), The Pandemic is a Portal, Financial Times, London, April 3.

Sharmer, O. and Kaufer, K. (2013), Leading from the Emerging Future: From Ego-System to Eco-System Economics, Berrett-Koehler Publishers, San Francisco, CA.

Sheldon, P. (2020), "Designing tourism experiences for inner transformation", Annals of Tourism Research, Vol. 83. 
Sheldon, P. and Fesenmaier, D. (2011), "Tourism education futures initiative (TEFI): activating change in tourism education", in Ateljevic, I., Pritchard, A. and Morgan, N. (Eds), The Critical Turn in Tourism Studies: Creating an Academy of Hope, Elsevier, New York, NY.

Sheldon, P. and Daniele, R. (Eds) (2016), Social Entrepreneurship and Tourism: Principles, Practices, Philosophies, Springer, New York, NY.

Stiglitz, J., Fitoussi, J. and Durand, M. (2019), Measuring What Counts: The Global Movement for WellBeing, The New Press, New York, NY, p. 240.

\section{Corresponding author}

Pauline J. Sheldon can be contacted at: psheldon@hawaii.edu

For instructions on how to order reprints of this article, please visit our website: www.emeraldgrouppublishing.com/licensing/reprints.htm

Or contact us for further details: permissions@emeraldinsight.com 